\title{
EL FETICHISMO DE LA FUENTE ETNOHISTÓRICA FIABLE: TEORÍAS Y TEXTOS DEL DEBATE SOBRE EL ESTADO INCAICO Y LA COMUNIDAD ANDINA (1) (Primera parte)
}

\author{
POR \\ JUAN J. R. VILLARIAS ROBLES \\ Dpto. de Historia de América \\ CSIC. Centro de Estudios Históricos. Madrid
}

En la bibliografía sobre el imperio inca aparece con frecuencia la opinión de que las diversas teorias sobre este imperio son el resultado de leer sus autores fuentes diferentes. Esta opinión ya fue expresada por M. Jiménez de la Espada en 1879 y después por investigadores como Ph. Means en 1928. A. Wedin en 1966 o F. Salomon en 1986. El artículo muestra que la opinión se basa más en la apariencia que en la realidad de los estudios de este imperio y del uso de sus fuentes.

En 1879, en su introducción a la publicación de Tres relaciones de antigüedades peruanas, el americanista español Marcos Jiménez de la Espada quitaba valor a las fuentes sobre el imperio inca más conocidas entonces -entre ellas las obras de Gómara, Acosta y el Inca Garcilaso-, comentando que "valiera más no haberlas escrito». En su lugar proponía la lectura de textos entonces inéditos o difíciles de encontrar, como las "tres relaciones" que publicaba (las de Santillán, Santacruz Pachacuti y el llamado "Jesuita anónimo»), confiando en que la discriminación en favor

(1) Este artículo es una versión ampliada y corregida del texto de la conferencia que dimos el 11 de marzo de 1993 en el Centro de Estudios Históricos del Consejo Superior de Investigaciones Científicas. en el marco del ciclo "Discurso etnográfico y análisis etnográfico del discurso", dirigido por Fermín del Pino Díaz y Carmen Ortiz (Febrero-Abril de 1993). Nuestro agradecimiento a ambos por su colaboración y sugerencias. El artículo es uno de los resultados de los proyectos del plan nacional de I + D "Discursos etnográficos y contextos histórico-sociales" (código de referencia: PB89-0051 ), hasta el 31 de octubre de 1993, y "Procesos inmigratorios en España: integración sociocultural..." (código SEC-93-0584), desde el 1 de febrero de 1994. 
de este segundo grupo de fuentes condujera a una aprehensión en sus justos términos del imperio incaico. Según él, eso no podía decirse de la idea que sobre este imperio prevalecía en su tiempo, difundida principalmente por el norteamericano William Prescott en su obra History of the Conquest of Peru, de 1847, traducida al castellano dos años más tarde por el mejicano Joaquín García Icazbalceta.

Jiménez de la Espada presuponía que la adecuada comprensión del imperio inca requería sólo una simple operación de inducción a partir de la lectura cuidadosa de un grupo determinado de fuentes, y que si había divergencia de pareceres sobre este imperio, eso se explicaba por el uso de fuentes distintas por los investigadores discrepantes. Desde 1879 otros estudiosos han insistido, aunque de maneras diversas, en la misma tesis; v. g., $\mathrm{H}$. Cunow en 1896, Ph. Means en 1928, R. Levillier en 1956, A. Wedin en 1966, F. Salomon en 1986.

En este artículo intentamos demostrar que a pesar de lo mucho que se ha repetido, y a lo largo de tanto tiempo, la tesis de Jiménez de la Espada carece de fundamento. La realidad de los estudios del imperio inca, desde sus orígenes más remotos, es que el tratamiento del problema de la comprensión de su estructura e historia, que obliga naturalmente a un análisis de sus fuentes, no se ha separado nunca del tratamiento (por otra parte legítimo) de problemas teóricos que trascienden el caso, con independencia de que los distintos investigadores hayan hecho mención o no a esta problemática más amplia; y la posición adoptada en ella ha condicionado siempre el análisis de la documentación. Dudosamente puede ser de otra manera y es tal vez por eso ingenuo pensar que la comprensión más cabal del imperio inca resulte alguna vez sólo de la lectura de fuentes.

Aunque esto debió tenerse en cuenta desde el principio, con mayor razón debe hacerse en los tiempos que corren, cuando la publicación de nuevas fuentes, la gran mayoría de ellas documentos de la administración colonial española que sustituyó al imperio incaico (aunque escasos, los textos narrativos o de carácter histórico convencional también han sido importantes; ahí está, por ejemplo, el espectacular hallazgo de la obra de Juan de Betanzos, publicada en 1987), ha adquirido un ritmo vertiginoso. 


\section{LA CONTROVERSIA SOBRE EL IMPERIO INCAICO}

El escritor peruano Mario Vargas Llosa se hacía no hace mucho una pregunta acerca de la conquista de Perú que muchos otros ya se habían hecho antes que él: la de cómo pudo ser posible que el poderoso y tan bien organizado imperio inca, que llegó a gobernar a más de veinte millones de personas y tenía en su haber tantos logros en la lucha de toda sociedad humana por la supervivencia, hubiera sido destruido por tan sólo unos cientos de personas, y además tan rápidamente (2)

Vargas Llosa no concedía una importancia decisiva a la superior tecnología bélica de los conquistadores españoles: «es verdad - escribía- que la pólvora, las balas y la embestida de bestias que nunca habían visto, paralizaban a los indios de un terror religioso y les infundían la sensación de estar luchando no contra hombres sino contra dioses, invulnerables a las flechas y las hondas con las que ellos acostumbraban combatir. Pero aún así la diferencia numérica era tal que aquel océano quechua, simplemente moviéndose, hubiera podido sumergir al invasor. ¿Qué lo impidió? ¿Cuál es la explicación profunda de esa derrota de la que el pueblo inca no se recuperó jamás?»

Para el famoso escritor peruano, la respuesta había que buscarla en lo que dicen las crónicas acerca de la captura por los españoles en Cajamarca del último emperador inca, Atahualpa. «En el instante mismo en que el emperador es capturado - señalaba-, antes de que empiece la batalla, sus huestes dejan de luchar, como maniatados por una fuerza mágica. La carnicería es indescriptible, pero de un solo lado: los españoles descargan sus arcabuces, clavan sus picas y sus espadas y avientan sus caballos contra una masa sonámbula, que, desde que ha visto capturado a su dios y señor, no atina a defenderse, ni siquiera a huir. En pocos minutos, el poderoso ejército [inca] (...) se desintegra como un pedazo de hielo en agua tibia» (3)

Tras lo ocurrido en Cajamarca, las restantes piezas del entramado creado por los incas fueron cayendo una detrás de otra

(2) Mario Vargas Llosa, "El nacimiento del Perú"; en José Miguel Oviedo (ed.), La edad del oro: crónicas y testimonios de la conquista del Perú, Barcelona, Tusquets y Círculo de Lectores, 1986, págs. 11-27. En diciembre de 1990, con ocasión del entonces próximo $\mathrm{V}$ centenario del primer viaje de Colón al continente americano, apareció la versión inglesa de este trabajo en la revista norteamericana Harper's, con el título "Questions of Conquest: What Columbus Wrought, and What He Did Not".

(3) Vargas Llosa [2], págs. 18-19. 
por la misma causa. En unos pocos años, su red de calzadas, sus templos y fortalezas, sus obras de irrigación, su compleja organización administrativa, estarían completamente arruinados. También su sistema de erradicación del hambre, pues la civilización de los incas había sido "capaz de producir - y distribuir lo producidode tal modo que todos sus súbditos comieran». Desde un punto de vista comparativo, ésta era la pieza de más valor, ya que «de muy pocos imperios en la historia se puede decir algo semejanten (4).

Pero el entramado era "vertical y totalitario", explicaba Vargas Llosa (5), y si bien comprendía obras admirables como las mencionadas, fueron sus mismas cualidades las que lo hacían débil y, por ello, la razón última de su destrucción:

prisionero el Inca, vértice hacia el que todas las voluntades convergían para recibir inspiración y animación, eje en torno al cual se organizaba la sociedad y del que dependía la vida la muerte de todos - desde el más grande hasta el más humilde-, nadie supo cómo actuar. Hicieron, entonces, lo único que podían hacer, con heroismo, sí, pero sin violentar los mil y un tabúes y preceptos que regulaban su existencia: dejarse matar (6).

Para el escritor peruano, las cualidades del orden incaico debieran sólo producirnos la fascinación que suscita la organización de las abejas (7) o de las hormigas (8): «laboriosa, eficiente, estoica». La organización incaica era en el fondo muy frágil porque no dejaba crecer algo fundamental para la supervivencia de toda sociedad: la libertad del individuo, que es la fuente del progreso. Fue ésta la aportación de los conquistadores españoles, hombres que en el mejor de los casos eran sólo unos aventureros valientes aunque hambrientos, y en el peor, gente cruel, medio analfabeta, codiciosa y pendenciera; en cualquier caso, personas dotadas con la libertad de iniciativa de que carecían los súbditos del Inca. Más que ninguna otra, fue esta diferencia la que decisivamente inclinó la balanza en favor de Pizarro y sus hombres (9).

Buen conocedor de las fuentes sobre el imperio inca (sirva como muestra su colaboración en la citada antología de J. M.

\footnotetext{
(4) Idem, pág. 18.

(5) Idem, pág. 19.

(6) Idem, pág. 19.

(7) Idem, pág. 22.

(8) Idem, pág. 27.

(9) Idem, págs. 19-27
} 
Oviedo), Vargas Llosa no basaba, sin embargo, su opinión en ninguna de ellas, fuera de una alusión vaga a lo narrado por los españoles que fueron testigos de los sucesos de Cajamarca. Recurría por el contrario al pensamiento del historiador peruano Raúl Porras Barrenechea, profesor suyo y uno de los investigadores que más tiempo y esfuerzo haya dedicado nunca al estudio de esas fuentes, falleciendo lamentablemente antes de poder escribir la obra que lo había requerido. El propio Vargas Llosa trabajó durante cuatro años en el proyecto (10).

El escritor se hacía eco asimismo del mencionado historiador norteamericano William Prescott y su obra, de la que aseguraba que, a falta de la obra soñada por Porras Barrenechea, continuaba siendo el mejor libro escrito sobre los incas y la conquista española de todos los tiempos (11).

\subsection{El modelo de Campanella/Prescott}

La opinión del escritor peruano es, que sepamos, la expresión autorizada más reciente de lo que nosotros llamamos «el modelo de Campanella/Prescott» de interpretación del sistema económico incaico. Difundido entre otros muchos investigadores por el mencionado Prescott, pero ya mucho antes de él por ensayistas como Michel de Montaigne (12) y Tommaso Campanella (13), este modelo, en la definición más general que podemos ofrecer de él aquí, presenta a todas las instituciones que sustentaban las condiciones materiales de vida de la población en el imperio inca como regidos o intervenidos por el Estado $y$, tras él, por el emperador y sus gobernadores. A pesar del carácter autoritario de su gobierno y de las diferencias sociales que promovía o sancionaba, o precisamente por eso, el emperador, "el Inca", tenía como atribución principal la de asegurar, de la mejor manera posible, dadas las condiciones demográficas y ecológicotecnológicas existentes, el proceso de producción y reproducción

(10) Idem, págs. 11-14.

(11) Idem, [2], pág. 14.

(12) Michael de Montaigne, Ensayos, en 3 vols. Edición y traducción de Dolores Picazo y Almudena Montojo. Madrid, Cátedra, 1985-87 [1580-1588]. La fecha entre corchetes es la de la primera edición de la obra.

(13) Tommaso Campanella, La Ciudad del Sol. Traducción y edición de E. G. Estébanez. Madrid, Mondadori España, 1988 [1609*, 1623]. La fecha seguida por un asterisco es aquella en la que la obra fue terminada por el autor. Daremos este dato siempre que exista una diferencia cronológica significativa entre la fecha de terminación de la obra citada y la de su primera edición. 
de las condiciones de vida de las muchas naciones o pueblos integrados en la formación político-social que encabezaba.

El sistema era un «despotismo patriarcal», en expresión de Prescott (14). Integraba un universo humano muy complejo: complejidad cuya expresión más visible eran esas naciones que lo componían, muchas de ellas de atuendo, hábitos, religión, tradición política y lengua distintas. Sin embargo, esta diversidad tenía poca importancia ante el hecho de que todas ellas ocupaban su puesto en un mismo entramado político-económico, que demandaba de ellas unas obligaciones pero que, en contraprestación, les hacía también acreedoras a sus resultados. Era esta relación de jerarquía y dependencia material con sus subordinados la principal fuente de legitimidad del poder del emperador y lo que sustentaba el carácter divino otorgado a su condición. El imperio incaico, en otras palabras, tenía una fundamental razón socioeconómica de ser, además de la razón política, militar y religiosa de otros imperios antiguos.

Frente a este modelo se encuentra otro en la bibliografía, que es el asumido, entre otros estudiosos, por Marcos Jiménez de la Espada. Hablaremos de él más adelante, tras hacer un resumen de las principales manifestaciones históricas del sistema de Prescott (15).

Este sistema, como ya hemos adelantado, aparece ya en sus aspectos esenciales en el mismo siglo XVI, el siglo de la caída del imperio incaico y la conquista española de su territorio. Así, cuando Michel de Montaigne quiso ensalzar la benevolencia y buen hacer de los incas poniendo como ejemplo la construcción de la calzada que unía Cuzco, la capital del Imperio, con Quito. A su juicio, la obra superaba con creces, por su "utilidad», "dificultad» y "nobleza» a cualquiera de las de Grecia, Roma o Egipto, cuanto más a las europeas de su tiempo. El humanista francés hablaba de ello en su ensayo "De los coches" (16), planteado en principio como una censura de los gastos de las cortes europeas. Esos gastos, según él, no servían para beneficiar al pueblo, sino

(14) William H. Prescott, "History of the Conquest of Peru". En History of the Conquest of Mexico and History of the Conquest of Peru, del mismo autor, págs. 723-1235. Nueva York, Random House, 1936 [1847], pág. 817.

(15) Haremos este resumen en función del objetivo que nos hemos planteado en este artículo. El lector interesado en los detalles de la polémica puede consultar nuestro trabajo El problema de la comprensión de las sociedades complejas antiguas: la controversia sobre el sistema económico del imperio incaico. Tesis doctoral. Universidad Complutense de Madrid, Facultad de Geografía e Historia, 1992.

(16) Montaigne, [12], vol. III. cap. 6. 
sólo para glorificar a los reyes y pagar a sus aduladores; lo que contrastaba con lo que pasaba en el Méjico azteca y el Perú de los incas, donde «jamás se nombra[ba] a un superior para su provecho, sino para el provecho del inferion. Ambas eran monarquías fuertes - las «más poderosas de aquel mundo, y quizá de éste», decía- y, sin embargo, servidoras de sus súbditos.

Pocos años más tarde, estas características (obras públicas admirables, monarquía fuerte e ilustrada, gobierno en provecho del inferior) serían relacionadas por Tommaso Campanella con la inexistencia de propiedad privada para plantear todo un modelo de sociedad utópica en contraposición a la realidad europea. La obra de Campanella, La cittá del sole, terminada en 1609, es tal vez la primera del género utópico inaugurado por Tomás Moro en incorporar datos de la organización inca, como opina $\mathbf{R}$. Rojas (17), e inicia una de las principales corrientes de pensamiento de que se ha nutrido el modelo de Campanella/Prescott. Entre sus principales exponentes cabe señalar, después de Campanella, a Veiras d'Alais y su Histoire des séverambes (Amsterdam, 1677) y a Morelly y su Basiliade (París, 1753). Todavía en el siglo $\mathrm{XX}$, el pensamiento socialista revolucionario no marxista debería mucho a esta doble tradición, utopista y primitivista a la vez, inspirada por el «ejemplo» de los incas (18). Lo mismo cabe decir del pensamiento indigenista en los países andinos después de 1920, representado por J. C. Mariátegui (19) y L. Valcárcel (20).

Paradójicamente, la otra gran tradición que ha sostenido al modelo es la del liberalismo clásico, representado por Prescott y, después de él, por C. Markham, L. Baudin, R. Porras Barrenechea, y últimamente parece que Vargas Llosa. Esta tradición tiene su origen en el modernismo ilustrado del siglo XVIII, especialmente en una antigua forma de teoría evolucionista llamada por R. L. Meek (21) «la teoría de los cuatro estadios».

(17) Ricardo Rojas, "Prólogo" a Comentarios reales de los incas [primera parte], del Inca Garcilaso de la Vega, edición de A. Rosenblat, en 2 vols.; vol. I, págs. vii-xxi. Buenos Aires, Emecé editores, 1943, vol. I, pág. xv.

(18) Ver por ejemplo Adolphe-Victor BonTHOuX, Le Régime économique des Incas. Paris, Marcel Giard, 1927.

(19) José Carlos MARIÁTEGUI, Siete ensayos de interpretación de la realidad peruana. Lima, Amauta, 1943 [1928].

(20) Luis E. Valcárcel, Mirador indio. Lima, Talleres Gráficos del Museo Nacional, 1937. Véase también su Historia de la cultura antigua del Perú, tomo I, vol. 1. Lima: Imprenta del Museo Nacional, 1943.

(21) Ronald L. MEEK, Social Science and the Ignoble Savage. Cambridge, Cambridge University Press, 1976. 
Esta teoría señalaba que todas las sociedades humanas pasan tarde o temprano por cuatro estadios sucesivos en su desarrollo, cada uno de ellos basado en un modo de subsistencia diferente: primero el de la caza, la pesca y la recogida de plantas y frutos silvestres; luego el del pastoreo, después el de la agricultura y finalmente el del comercio. Cada uno de estos modos de subsistencia determina el carácter del resto de las condiciones de vida en una sociedad en su estadio respectivo: el sistema político, las ideas y creencias, y la organización de las relaciones sociales.

Al aplicarse la teoría al caso del imperio inca, éste aparecía como contradictorio. Su modo de subsistencia dominante parecía ser el de la agricultura, pero el pastoreo tenía también una gran importancia; en cualquier caso, las grandes dimensiones del imperio y su elaborada organización política eran más bien propios del cuarto y último estadio, el del comercio. Por otro lado, la sociedad desconocía la propiedad privada, que era una condición necesaria para el comercio y se suponía que hacía su aparición con el pastoreo, el segundo estadio.

Aunque no la más antigua, ésta era una de las primeras manifestaciones de los problemas que siempre le ha dado el imperio inca a todo esquema evolucionista derivado de la experiencia europea. Muchos defensores de la teoría de los cuatro estadios (Corneille de Pauw, el abad Raynal, el abad Genty, William Robertson) racionalizaron las "anomalías» del caso en el sentido de aceptar como excepcional la descripción que hacía del imperio inca la literatura utópica y el primitivismo (ambos géneros, muy populares en el siglo XVIII), pero rechazando el supuesto bienestar espiritual que derivaba necesariamente de las virtudes de la organización política y económica. Esos autores consideraron ese bienestar sencillamente increíble, precisamente por las "anomalías» que a su juicio presentaba el caso, especialmente la que cabía inferir de la falta de propiedad privada. Aprovechaban así para hacer valer la causa del modernismo y exponer las virtudes del "estadio comercial» (el de la Europa noroccidental de su tiempo) frente al primitivismo y las sociedades que sólo conocían la propiedad común, que por eso, según ellos, estaban menos desarrolladas.

Robertson fue el más elocuente de todos, escribiendo que el poder absoluto de los reyes incas

parece haber estado uniformemente acompañado de la atención prestada al bienestar de sus súbditos. No fue el afán de 
conquista (...) lo que impulsó a los incas a extender sus dominios, sino el deseo de difundir las bendiciones de la civilización y el conocimiento que poseían entre el pueblo bárbaro al que sometieron (22).

El problema era que con ello la población se vio atenazada por un malsano "espíritu anti-guerrero" ("unwarlike spirit») que para Robertson explicaba el, a su juicio, rápido desplome del Imperio tras la llegada de los españoles (23).

En 1847, Prescott, dentro ya del liberalismo clásico, repetiría la misma idea (como también Vargas Llosa 140 años más tarde). El gobierno de los incas era un "despotismo patriarcal», el régimen «más opresivo de todos, pero también el más suave». El soberano lo poseía y controlaba todo, pero su propósito - y el de su bien organizada administración- no era sino el bienestar del pueblo. Para hacerse obedecer no necesitaba recurrir a la fuerza, como hacían los reyes de otras naciones; le bastaba con la opinión, especialmente la religiosa, cuya importancia recordaba el poder de la Iglesia en la Edad Media europea (24).

El lado negativo del sistema era la falta en el pueblo de «ambición, de avaricia, de amor al cambio, del mórbido espíritu del descontento, de esas pasiones que más agitan las mentes de los hombres" (25). Al historiador norteamericano no le gustaba especialmente que la población no tuviera "amor al cambio", que atribuía al esfuerzo que los incas habrian hecho por «infundir en sus súbditos un espíritu de calma y obediencia pasiva, una conformidad perfecta con el orden establecido" (26).

Prescott había hecho un análisis exhaustivo de las fuentes publicadas en su tiempo, así como de otras que se hallaban entonces inéditas, como los informes de Juan Polo de Ondegardo (27), la segunda parte de la crónica de Pedro de Cieza de

(22) William RoBertSon, History of America incluye "The Posthumous Volume, Containing the History of Virginia, to the Year 1688, and of New England, to the Year $1652^{\prime \prime}$, en 2 tomos; Albany, Nueva York, E. \& E. Hosford, 1822 [1777]; libro 6, párrafo 17.

(23) Idem, [22], libro 7, párrafo 51.

(24) Prescott, [14], pág. 817.

(25) Idem, págs. 762-763.

(26) Idem, pág. 763.

(27) Conocidos después como "Informe al licenciado Briviesca de Muñatones sobre la perpetuidad de las encomiendas en el Perú", de 1561, y "Relación de los fundamentos acerca del notable daño que resulta de no guardar a los indios sus fueros y de la orden que los indios tenian en dividir los tributos entre sí", de 1571; el segundo también conocido como "Relación acerca del linaje de los incas y cómo conquistaron, y acerca del notable daño que resulta de no guardar a los indios sus fueros". 
León (28) y el fragmento de la de Juan de Betanzos que publicaría más tarde Marcos Jiménez de la Espada (29). Pero como Robertson, y también como de Pauw, Raynal y Genty, Prescott no fundamentaba lo que para él eran las deficiencias del sistema en fuente alguna; tan sólo en una racionalización nacida de sus presupuestos. La organización autocrática pero eficiente y benévola de que hablaban las fuentes no podía permitir el desarrollo del individualismo en el pueblo, al impedir que el «individuo" (por oposición a la «sociedad») pudiera beneficiarse espiritual o materialmente de la enorme cantidad de trabajo social que el Estado movilizaba. Y eso era, en síntesis, lo verdaderamente opresivo del régimen, y la causa de fondo de la derrota frente a los españoles (30). El individualismo era uno de los valores fundamentales del pensamiento de Prescott; así lo confiesa en su libro, y en el mismo pasaje (31) compara desfavorablemente en este aspecto al imperio incaico con la joven república de los EE.UU.

Fue la tradición liberal inaugurada por el historiador norteamericano la verdadera autora de una idea que se haría muy famosa en los estudios del imperio inca: la de que su sistema político-económico era un socialismo o comunismo de Estado avant la lettre. El francés E. Carrey en 1875 (32) y el suizo J. J. von Tschudi en 1876 (33) fueron de los primeros en expresarla. Ya en el siglo XX les seguirían C. Markham (34), L. Baudin (35), V. W. von Hagen (36) y J. Alden Mason (37), por citar sólo los

(28) Conocida después como "Segunda parte de la crónica del Perú, que trata del señorío de los incas yupanquis y de sus grandes hechos y gobernación", o simplemente "El señorío de los incas"; de 1550. Prescott atribuyó por error esta fuente a Juan de Sarmiento, quien fue presidente del Consejo de Indias bajo el reinado de Felipe II.

(29) Juan de Betanzos, Suma y narración de los incas que los indios llamaron capaccuna que fueron señores de la ciudad del Cuzco y todo lo a ella subjeto. Edición de Marcos Jiménez de la Espada. Madrid, Biblioteca Hispano-Ultramarina, vol. V, $1880\left[1551^{*}\right]$.

(30) PrescotT, [14], págs. 819-820.

(31) Idem, págs. 817-820.

(32) Emile CARREY, Le Pérou: Tableau descriptif, historique et analytique des êtres et des choses de ce pays. Nueva Orleans, Hebert, 1875.

(33) Johann Jakob Von TschuDI, "Ollanta: Ein Altperuanisches Drama Aus Der Kechuasprache". En Denkschriften Der Kaiser-lichen Akademie Der Wissenschaften, Philoso-phisch-Historische Classe, vol. 24, 1876, págs. 167-384.

(34) Clements Markham, The Incas of Peru. Londres, Smith y Elder, 1910.

(35) Louis BAUDIN, L'Empire socialiste des Inka. Paris, Institut d'Ethnologie, Travaux et Mémoires de l'Institut d'Ethnologie, vol. V, 1928.

(36) Victor Wolfgang Von HaGEN, Realm of the Incas. Nueva York: The New American Library, 1957.

(37) J. Alden Mason, The Ancient Civilizations of Peru. Edición corrregida y ampliada. Baltimore, Penguin, 1968 [1957]. 
más influyentes. Haciendo abstracción de cambios formales, como el del tono del discurso o los términos utilizados (38), todos estos autores reprodujeron el fondo del argumento de Prescott: que los incas estaban a la cabeza de una organización impresionante de los recursos disponibles que aseguraba el bienestar material de la población; su gobierno era intervencionista en extremo, y por eso mismo reprimía la iniciativa privada y condenaba a la sociedad al estancamiento a largo plazo, así como a la vulnerabilidad frente a amenazas nuevas y repentinas. La mayoría de estos investigadores hacía especial hincapié en este "problema» en contra del socialismo o comunismo contemporáneo, difiriendo en ello (y sólo en ello) con los cultivadores del género utópico y la tradición primitivista, para quienes la ausencia de la propiedad privada que suponía un régimen autocrático pero benevolente como el de los incas era la mejor garantía de la felicidad general, tanto en lo material como en lo espiritual.

Otros investigadores ajenos a la tradición liberal estuvieron de acuerdo con la caracterización de "socialista" o "comunista" atribuida a ese régimen, aunque se abstuvieron de extrapolar esta interpretación al mundo contemporáneo. Es el caso de E. J. Thompson (39) o H. Castro Pozo (40). Todavía otros no adoptaron esa denominación, o la rechazaron abiertamente, por considerarla un anacronismo, como hicieron R. A. Latcham (41), E. Romero (42) o J. Rowe (43); no obstante, estos investigadores estuvieron de acuerdo con la tesis central de una economía dirigida por el Estado de la que dependía el nivel de vida de la población. Rowe, por ejemplo, escribió:

(38) Alden Mason, por ejemplo, prefería decir que el régimen incaico era el "Estado de bienestar [Welfare state] por excelencia". Hagen opinaba que el régimen se parecía al soñado por los utópicos, al tiempo que lo comparaba con el de la Unión Soviética.

(39) Eric J. Thompson, Archaeology of South America. Chicago, Field Museum of Natural History, 1936.

(40) Hildebrando Castro Pozo, "Las comunidades indígenas del Perú"; en Dario Sante Marie S. (ed.), Perú en cifras: 1944-1945, págs. 158-174. Lima, Ediciones Internacionales.

(41) Ricardo A. LATChaM, "El dominio de la tierra y el sistema tributario en el antiguo imperio de los incas"; en Revista Chilena de Historia y Geografía, vol. 52, 1927, págs. 201-57.

(42) Emilio Romero, Historia económica y financiera del Perú: Antiguo Perú y Virreynato. Lima, Torres Aguirre, 1937.

(43) John H. Rowe, "Inca Culture at the Time of the Spanish Conquest". En Julian B. Steward (ed.), Handbook of South American Indians, vol. 2, págs. 183330. Nueva York, Cooper Square, 1946. 
El gobierno de los incas era un despotismo sin adjetivos, cuyo poder derivaba de los seres naturales que protegían al emperador, y de hecho de la fuerza militar que éste controlaba. Su preocupación paternalista por el bienestar material de sus súbditos no era, como los mismos emperadores admitieron, sino un ilustrado interés propio, ya que se daban cuenta de que un pueblo sano y feliz trabaja mejor y produce más que uno que sufre privaciones e injusticias (...). Si el sistema inca debiera o no considerarse como socialismo depende totalmente de la definición de socialismo (44)

El término "socialismo", así como el equivalente de "comunismo de Estado", o "Estado de bienestan, irían desapareciendo gradualmente de la bibliografía a partir de 1950. Sin embargo, la tesis central del modelo de Campanella/Prescott cobraría un nuevo impulso por esos mismos años, y hasta la década de los 70, gracias a la influencia entonces de la perspectiva ecológicocultural en antropología, también conocida como «evolucionismo multilineal" o "neoevolucionismo" (45). A diferencia del evolucionismo "unilineal" anterior, la nueva teoría distinguía diversas secuencias de desarrollo en el devenir de las sociedades humanas, advirtiendo que en ese desarrollo había tenido una importancia determinante el proceso de adaptación al medio natural. Una de esas secuencias, o "líneas», fue la que siguieron lo que Steward llamó "primeras civilizaciones" (46) y K. Wittfogel "sociedades hidráulicas u orientales», o "despotismos orientales» (47), entre los que se encontraba el imperio inca. Todas estas sociedades, según estos autores, vieron el Estado surgir por primera vez en la historia y luego desarrollarse con el fin de asegurar el creci-

(44) Idem, pág. 273

(45) Julian H. STEWARd, "Development of Complex Societies: Cultural Causality and Law: A Trial Formulation of the Development of Early Civilizations"; en Theory of Culture Change: The Methodology of Multilinear Evolution, del mismo autor; Urbana, Illinois, University of Illinois Press, 1949, págs. 178-209. "Cultural Evolution in South America"; en Walter Goldschmidt y Harry Hoijer, eds., The Social Anthropology of Latin America: Essays in Honor of Ralph Leon Beals, Los Angeles: University of California, Latin American Center, 1970, págs. 199-223.

(46) Idem, 1949.

(47) Karl A. WITTFOGEL, "Developmental Aspects of Hydraulic Societies"; en Julian H. Steward et alii, eds., Irrigation Civilizations: A Comparative Study; Washington, D.C., Pan-American Union Social Science Monographs, 1955, págs. 43-52. "The Hydraulic Civilizations; en William L. Thomas, Jr., ed., Man's Role in Changing the Face of the Earth; Chicago, University of Chicago Press, 1956, págs. 152-164. Oriental Despotism: A Comparative Study of Total Power. New Haven, Connecticut: Yale University Press, 1957.

Véase también Marvin HARRIS, Cannibals and Kings: The Origins of Cultures. Nueva York, Random House, 1977, págs. 233-247. 
miento económico demográfico a largo plazo, pues estaban emplazadas en espacios naturales pobres o de difícil adaptación y ésa era la única forma de obtener un nivel de vida comparable al de otras sociedades del mismo nivel tecnológico pero asentadas en condiciones ecológicas más favorables. En el caso de la sociedad andina en los siglos XIV y XV, el Estado inca tuvo esa función y es desde esta perspectiva como hay que entender su origen y posterior desarrollo (48).

\subsection{El modelo de Smith/Cunow}

Pero como ya hemos adelantado, en la bibliografía cabe identificar un modelo alternativo al de Campanella/Prescott y con una historia paralela, aunque no tan antigua. Es el que nosotros denominamos "modelo de Smith/Cunow", en honor también a dos de sus más antiguos y principales representantes: el padre de la economía clásica, el escocés Adam Smith, quien escribió sobre los incas en su famoso tratado sobre la riqueza de las naciones (49), y el sociólogo alemán Heinrich Cunow, quien se interesó en el tema a finales del siglo XIX (50). De acuerdo con este segundo modelo (que empezamos definiendo también aquí de manera general), la producción y reproducción de las condiciones de existencia en el imperio incaico, contrariamente a lo propuesto en el modelo de Campanella/Prescott, debía poco al Estado. Estaban por el contrario aseguradas por la organización y costumbres de los muchos pueblos conquistados por los incas, en los que tenían una importancia determinante el derecho colectivo a la riqueza y los sistemas de obligaciones recíprocas basados en el parentesco. Ese derecho y esas obligaciones se daban normalmente entre personas pertenecientes a una misma comunidad local o a dos o más comunidades, aunque dentro del mismo pueblo; sólo en raros casos las relaciones trascendían ese ámbito y ponían en relación a pueblos distintos.

El Estado era un factor negativo en esta realidad económica

(48) STEWARD, [45], 1970, págs. 214-215; WiTtFogel, [46], 1955, págs. 46-49 y HARRIS, [47], págs. 169-189, 233-247.

(49) Adam SMITH, The Wealth of Nations [1776]; edición de E. Cannan. Nueva York, Random House, 1937 [1776].

(50) Heinrich CunOw, Las comunidades de aldea y de marca del Perú antiguo, traducción de María Woitscheck; Paris, Le Livre Libre, 1929 [1890]. La organización social del imperio de los incas: investigación sobre el comunismo agrario en el antiguo Perú; traducción de María Woitscheck; Lima, Librería Peruana, 1933 [1896]. 
atomizada, ya que no hacía sino detraer parte de la riqueza que creaba la organización de las naciones sometidas para emplearla en alcanzar o asegurar tan sólo los fines políticos y materiales de la clase social que gobernaba el Imperio, que era la formada por los incas y sus clientes y aliados entre los reyes y jefes de algunas de las entidades políticas incorporadas a él. Así pues, según este segundo modelo, el Estado no tenía ninguna función económica, excepto si se reduce el ámbito del problema de las condiciones de la reproducción social al de las condiciones de reproducción del propio Estado y de la clase a la que servía.

Este modelo alternativo tuvo su primera expresión en la teoría modernista de los cuatro estadios mencionada antes, si bien fue una expresión minoritaria entonces. El padre de la economía clásica, A. Smith, quien era otro de los principales exponentes de la teoría, resolvió el problema que le planteaba el caso del imperio incaico de una manera radicalmente diferente a la que habían elegido de Pauw, Raynal, Genty y Robertson: la de negar credibilidad a la tradición primitivista y utópica. Para Smith lo decisivo del caso eran las noticias en las fuentes que indicaban ausencia de escritura, de moneda, de arado romano, de hierro y animales de tracción, así como de un desarrollo suficiente de la división del trabajo, todo lo cual significaba para el padre de la economía clásica que el imperio inca no pudo haber sostenido una población numerosa, sino inferior a la ya escasa de la subsiguiente época colonial (51). Si bien pensaba que los incas habían estado más adelantados que los aztecas, también estaba convencido de que tanto unos como otros habían sido, en cuanto a «letras, agricultura y comercio (...), mucho más ignorantes que los tártaros de Ucrania" (52), siendo las tres sociedades muy inferiores a las de "China, India y Japón» (53).

Smith venía a decir que el denominado imperio de los incas era en realidad una sociedad muy primitiva, tribal, en la que la vida de las personas giraba en torno a las reglas que imponía la comunidad local a la que pertenecieran. El imperio inca no era ninguna civilización y menos aún una sociedad ideal que la filosofía social y política de nuestro tiempo debiera tomar como referencia. Jiménez de la Espada expondría fundamentalmente la misma idea en 1879. Los evolucionistas unilineales del siglo XIX, con L. H. Morgan y sobre todo H. Cunow a la cabeza,

(51) SMITH, [49], págs. 203, 535.

(52) Idem, pág. 203.

(53) Idem, pág. 416. 
abonarían este planteamiento con la comparación con estudios etnográficos de sociedades tribales contemporáneas; comparación que sugería que el imperio incaico no era más que una confederación de tribus, en cuya organización y desenvolvimiento habían sido determinantes los principios del clan clásico que Morgan formulara en 1851 y 1877 tras estudiar la organización de los iroqueses, en el nordeste de los EE.UU., y cotejarla con las noticias en la Antigüedad sobre el genos griego y la gens romana. Cunow pudo asi escribir contra Prescott y sus seguidores que

las instituciones del imperio de los incas nada tienen que ver con el socialismo imperial o democrático. Lo que hoy se estima en esas instituciones como semejante a nuestros conceptos actuales del socialismo, esto es, el derecho común sobre la tierra, animado de un espíritu recíproco de solidaridad, no es otra cosa que aquel comunismo primitivo que se encuentra en diferentes tribus como producto natural de las formas sociales fundadas en las relaciones de parentesco (54).

Siendo marxista, Cunow deseaba atacar por la base el argumento de aquellos que ponían como ejemplo del socialismo por venir su idea del socialismo incaico. El régimen incaico no era socialista, decía, y además los incas «oprimían" a la población, esto es, a las tribus andinas que practicaban el «comunismo primitivo", lo que ya de por sí debiera ser suficiente para rechazar esa caracterización; por ejemplo, los incas «acostumbraban dividir una tribu recién subyugada en dos partes aproximadamente iguales (...) a fin de mantener [entre ellas] (...) cierto antagonismo, [y así] impedir (...) una acción conjunta contra el Imperio" (55).

Cunow interpretaba así la división por mitades que caracterizaba a muchos pueblos de los Andes en el momento de producirse la llegada de los españoles, que el investigador alemán relacionó con los datos de las fuentes que indicaban que en el Imperio había grandes diferencias políticas y sociales. Sin embargo, la apreciación contradecía su tesis de que el Imperio no había sido más que una confederación tribal y su régimen socioeconómico había sido el "comunismo primitivo", teóricamente incompatible con una sociedad de clases. Cunow no supo resolver la contradicción por su apego al esquema de Morgan y ello facilitó que, a pesar de sus críticas, aparecieran después de él

(54) Cunow, [50], 1929 [1890], pág. 12.

(55) Idem, 1933 [1896], págs. 54-55. 
nuevas versiones del modelo de Prescott, en especial la de C. Markham en 1910.

Pero en los años 20, la crisis del evolucionismo unilineal, y en especial del esquema de Morgan, incapaz de explicar el origen y desarrollo de sociedades complejas diferentes a las europeas, así como transformaciones revolucionarias como la acontecida en Rusia a partir de 1917, permitió dar unas nuevas señas de identidad al modelo de Smith/Cunow. El orden incaico podía perfectamente ser opresivo para el pueblo andino y, a la vez, las bases económicas de la sociedad estar ancladas en el colectivismo de comunidades locales, organizadas sobre la base del parentesco. Esto es lo que plantean desde entonces otros investigadores marxistas o próximos al marxismo, como el también alemán $\mathrm{H}$. Trimborn (56), el suizo A. Métraúx (57) y el rumano afincado en los EE.UU. J. V. Murra; éste, sin duda, el más influyente en las últimas décadas de historia de la controversia (58). Cabe asimismo destacar al liberal argentino R. Levillier (59); el suyo es uno de los raros casos en que el liberalismo clásico ha estado relacionado con el modelo de Smith/Cunow.

Como Cunow antes que ellos, Trimborn, Métraux y Murra combatieron con energía la noción de que el régimen incaico había sido socialista o algo que se le pareciera; noción que, como hemos visto, la mayoría de los defensores del modelo de Campanella/Prescott continuaba difundiendo por los mismos años. Trimborn escribió que la supuesta política social de los incas era más aparente que real, pues su imperio

fue un Estado integrado por clases con muy resaltantes diferencias económicas y sociales, en el cual lo más notorio era la distinción entre una capa de señores y otra de siervos (60).

El régimen era "feudal», decía (61); la explotación de los siervos

(56) Hermann Trimborn, "Las clases sociales en el imperio incaico"; Revista de la Universidad Católica del Perú, Lima, vol. 3, 1943 (1927), págs. 212-219, 325332, 403-418, 476-490, 551-559.

(57) Alfred Metraux. Les Incas. Paris, Editions du Seuil, 1962.

(58) Citemos, entre sus muchos trabajos, La organización económica del Estado inca, traducción de Daniel R. Wagner, Ciudad de México, Siglo XXI Editores, 1978 [1955*]; así como la recopilación de artículos Formaciones económicas y políticas del mundo andino, Lima, Instituto de Estudios Peruanos, 1975.

(59) Roberto Levillier, Los incas. Sevilla, Escuela de Estudios Hispanoamericanos, 1956.

(60) TRIMBORN, [56], pág. 212.

(61) Idem, págs. 479, 482. 
"encontraba su límite tan sólo allá donde el interés de los conquistadores [incas] estaba frente a la necesidad de conservar sus tributarios»; éstos, por su parte, continuaban con su «organización económica" de siempre, en la que «cada uno era protegido contra el hambre, ya sea por la índole del derecho hereditario, ya sea por la protección colectiva de su comunidad" (62).

Métraux no calificó el régimen incaico de "feudal», pero su caracterización de él fue muy parecida a la de Trimborn. Escribió, por ejemplo, que la población

estaba sometida al despotismo de una casta (...). El colectivismo agrario no existía excepto a nivel de las comunidades, los ayllus, y éste era un sistema ya antiguo, con paralelismos tanto en el viejo como en el nuevo mundo (...). Sólo parcialmente estaba la producción destinada a cubrir las necesidades de la población, y todo el excedente revertía a la casta dominante y sus funcionarios.

Es cierto que el excedente era en parte redistribuido, pero en forma de alimentos y utillaje a equipos de trabajadores [cuando éstos trabajaban para el Estado] y a soldados, o como presentes a nobles, sacerdotes y funcionarios. La ayuda a los ancianos y enfermos, que a uno le tienta el compararla con nuestra legislación sobre seguridad social, era un asunto de la aldea, no del Estado. Esta obligación simplemente expresaba la vieja solidaridad de grupo, todavía presente hoy entre los primitivos agricultores de la Amazonía y los campesinos del Perú moderno (63).

Murra hizo un gran esfuerzo por reconstruir en detalle esta vieja solidaridad de grupo en los Andes:

[El cronista] Blas Valera llama a esto la 'ley de hermandad': que todos los habitantes de la aldea 'se ayudasen unos a otros a barbechar y a sembrar y a coger sus cosechas (...) sin llevar paga ninguna'. Los recién casados tenían derecho a que se les construyera una casa (...). Si la tarea era de mayor envergadura e involucraba a varios linajes, éstos se turnaban hasta terminar el trabajo (...).

No puede dudarse de que se había élaborado una fórmula minuciosa para la reciprocidad, especialmente en lo que toca a las tareas agrícolas (...). Las tareas eran asignadas a las unidades domésticas, no a los individuos, y las más extendidas de éstas,

(62) Idem, págs. 327, 406.

(63) Metraux, [57], pág. 112. 
por incluir a muchos hijos adultos solteros $\mathrm{u}$ otros parientes en la misma situación, cumplian más rápido con sus obligaciones (...). Además de los intercambios corrientes en la agricultura y la construcción de casas, las fuentes indican que la comunidad étnica se hacía responsable de los ancianos, las viudas y los huérfanos, los enfermos y los inválidos. Su condición no les impedía recibir el correspondiente lote de tierra, pero, puesto que no podían cultivarlo, 'la comunidad' lo hacía por ellos (64).

La atribución de la «ley de hermandad» andina a los incas era para Murra un viejo error que los propios incas habrían sido los primeros en difundir:

Es difícil saber a cuántos ciudadanos habían convencido los incas en 1532, pero su (...) esfuerzo ideológico por transferir los mecanismos de la tradicional reciprocidad andina al nivel de un Estado tuvo en parte éxito: convenció a los cronistas europeos y a algunos modernos investigadores de que la Corona inca controlaba la totalidad de la vida económica del país en función esencialmente del bienestar general (65).

Levillier difería de Trimborn, Métraux y Murra sólo en la terminología aplicada. El llamaba al orden incaico «un engranaje comunista", aunque lo entendía en un sentido acorde con las tesis de aquéllos. Escribió así que

la unidad del Imperio era (...) más extendida que profunda (...). La impresión de los españoles al invadir el Imperio fue que todo era incaico. No distinguieron de inmediato que bajo las exteriorizaciones de un poder único, habían conservado las naciones doblegadas (...) su propia personalidad (66).

Levillier consideraba que el virrey Francisco de Toledo (15691581) y sus asociados habían tenido razón al calificar el dominio de los incas de ilegítimo y opresor, contra la opinión de Bartolomé de Las Casas y otros, y dedicó muchos años de su vida a publicar documentos sobre la política y el pensamiento de este virrey.

En los años 60 y 70, Murra aprovechó la publicación de

(64) Murra, [58], 1978 [1955*], págs. 137-138.

(65) John V. MURRA, "On Inca Political Structure", en Verne F. Ray, ed., Proceedings of the 1958 Annual Spring Meeting of the American Ethnological Society (Albany, Nueva York); Seattle, Washington, The Society, 1958, págs. 30-41; págs. 34-35.

(66) 'Levillier, [59], pág. 76, pág. 250. 
documentos de la administración colonial española para enriquecer su tesis con una reconstrucción de los aspectos ecológicos del orden pre-incaico. Los mecanismos de reciprocidad social que distinguían a este orden tenían por escenario, no territorios continuos, los de cada uno de los pueblos más tarde integrados en el imperio incaico (que por ello vivirian geográficamente separados entre sí), sino discontinuos; eran como «islas" que formaban "archipiélagos», según su expresión, repartidas por todos los pisos ecológicos de los Andes, muchas de las cuales eran, además, compartidas por dos o más pueblos. Este sistema de "archipiélagos» era una sabia manera de adaptarse a la verticalidad ecológica andina, que ofrece recursos muy diferentes (marítimos, agrícolas, mineros, pastoriles) según la altitud de la cordillera. Lo que unía a cada pueblo con sus «islas» eran los mismos mecanismos de reciprocidad de su orden político económico, que regían su aprovechamiento al tiempo que daban contenido a la relación con otros pueblos interesados en los mismos recursos (67).

Coherentemente con su posición en los años 50, para Murra la formación del imperio incaico supuso una ruptura con esta cultura ecológica andina. Aunque los incas crearon sus propias «islas», su objetivo ya no era el aprovechamiento óptimo de los recursos de los Andes para asegurar el bienestar de la población, como ocurría con los archipiélagos preincaicos, sino su propio interés como élite de un imperio; como él mismo escribió, bajo los incas «la previa concepción del archipiélago ecológico estaba en neta contradicción con su reutilización y proyección con fines militares» (68). Murra continuaba negando así que el régimen incaico tuviera una fundamental razón económica de ser, como defendía la tradición de Campanella/Prescott y en concreto su expresión más reciente, la de los neo-evolucionistas. Esa función

(67) Véanse como principales exponentes de estas ideas los artículos siguientes del investigador rumano: "Social Structural and Economic Themes in Andean Ethnohistory", en Anthropological Quaterly, vol. 34, 1961, n 2, págs. 4759; "La visita de los chupachu como fuente etnológica", en Visita de la provincia de León de Huánuco en 1562, por Iñigo Ortiz de Zúñiga, visitador: Tomo I, visita de las cuatro waranqa de los chupachu, John V. Murra, ed., Huánuco, Peru: Universidad Nacional Hermilio Valdizán, Facultad de Letras y Educación, 1967, págs. 381-406; "Un reino aymara en 1567", en Formaciones económicas y Politicas del mundo andino, John V. Murra, ed., Lima, Instituto de Estudios Peruanos, 1975 [1968], págs. 193-223; "El control vertical de un máximo de pisos ecológicos en la economía de las sociedades andinas", en Formaciones ..., 1975 [1972], págs. 59-115.

(68) MurRa, [67], 1975 [1972], págs. 114-115. 
la seguían teniendo las instituciones de los pueblos conquistados, creadores del «archipiélago ecológico».

La paciente labor de Murra de reconstrucción del orden andino, antes y después del dominio de los incas, fue saludada con el aplauso de un numeroso grupo de investigadores; sin embargo, la interpretación de la documentación hecha por el investigador rumano no escapó a la polémica. Conviene tener presente que esa interpretación debía mucho a la publicación de textos de la administración colonial, que aunque importantes, eran reveladores, antes que nada, del estado de la cultura indígena posterior a la intervención de los españoles, nada fácil de intercambiar con la situación anterior. Después volveremos sobre este problema. En relación con el periodo incaico, además, la interpretación contradecía dos de las fuentes más respetadas (incluso por él mismo): La crónica del Perú, de Cieza de León, y el Informe al licenciado Briviesca de Muñatones sobre la perpetuidad de las encomiendas, de Polo de Ondegardo, que ya hemos citado al hablar de Prescott. Tanto Cieza como Polo establecen que muchas de las kislas" del archipiélago inca eran claramente parte del sistema general de reproducción social (69). No puede sorprender por ello que ya en 1898 el español Joaquín Costa llamara la atención sobre el texto de Polo para calificar el régimen de los incas de "socialismo de Estado", en línea con el modelo de Campanella/Prescott.

En 1976, el norteamericano John Earls, sirviéndose principalmente de la arqueología, que cotejó con lo escrito por el cronista Bernabé Cobo (70), muy influido a su vez por Polo, ofreció una interpretación de la cultura ecológica en el periodo inca diferente de la de Murra pero asimismo en línea con el modelo de Campanella/Prescott (71).

Aparte de destacar la función económica del sistema de archipiélagos, Earls consideró un serio error ignorar su relación

(69) Pedro de Cieza de León, "Crónica del Perú: parte primera", edición de Carmelo Sáenz de Santa María; en Obras completas de Pedro de Cieza de León, vol. 1 (Monumenta Hispano-Indiana II.1), págs. 1-145; Madrid, Consejo Superior de Investigaciones Científicas, Instituto Gonzalo Fernández de Oviedo, 1984 [1553]; véase el capítulo 99. Juan POLO DE ONDEGARDO, "Informe al licenciado Briviesca de Muñatones sobre la perpetuidad de las encomiendas en el Perú"; edición de C. A. Romero en Revista Histórica, órgano del Instituto Histórico del Perú, Lima, vol. 13, 1940 [1561*], págs. 125-196; passim.

(70) Bernabé Сово, Historia del Nuevo Mundo, 4 vols.; Sevilla, Rasco, 1890$95\left[\right.$ ca. $\left.1653^{*}\right]$.

(71) John EarLS, "Evolución de la administración ecológica inca"; en Revista del Museo Nacional, Lima, vol. 42, 1976, págs. 207-245. 
con las famosas terrazas de los Andes hechas en el periodo incaico. Tras un estudio de las de Moray, en la sierra meridional de Perú, no lejos de Cuzco, el investigador norteamericano concluyó que eran un medio de adaptación a la verticalidad ecológica andina que complementaba y hacía mayor el efecto del archipiélago. Entre otras propiedades, las terrazas ofrecen un cambio térmico más rápido en relación con la altitud que el registrado en las pendientes naturales de los Andes. En la latitud de Cuzco, por ejemplo, el ritmo de cambio térmico medio es de 1 grado centígrado por cada $182 \mathrm{~m}$. de altitud; sin embargo, en las terrazas de Moray, que son de planta circular, Earls descubrió que el cambio medio es de 1 grado por cada $3,5 \mathrm{~m}$. de altitud; de manera que, para territorios como la región de Cuzco, un archipiélago completo que sin las terrazas habría abarcado miles de metros de pendiente natural, podía ser concentrado gracias a ellas en un tramo de pendiente de tan sólo unas decenas de metros.

Earls razonó que una concentración así de la amplitud ecológica de los Andes, conjuntada con el sistema de archipiélagos para otras zonas, tuvo que haber hecho muy racional la organización de la producción (habría ahorrado, por ejemplo, una gran cantidad de trabajo en la asignación y movilización de recursos) y facilitado la planificación central del ciclo agrícola anual (72).

El investigador norteamericano hacía esta interpretación alternativa de la adaptación vertical andina en época de los incas desde la perspectiva ecológico-cultural o neoevolucionista, mencionada antes.

\section{LA CONTROVERSIA Y LAS FUENTES SOBRE EL IMPERIO INCA}

Subyacente a sus diversas manifestaciones históricas, la alternativa de los dos modelos, el de Campanella/Prescott y el de Smith/Cunow, constituye lo que para nosotros es el fondo de la controversia sobre el sistema económico incaico. La cuestión en torno a la cual gira este debate, como se infiere de lo expuesto en las páginas anteriores, es la de qué agentes e instituciones y relaciones entre unos y otras, hacían posible el sostenimiento de una formación político-social como este imperio, con una población que se ha estimado en más de 20 millones de personas y de

(72) Idem, págs. 135-140. 
características estructurales extrañas desde el punto de vista de la evolución cultural en Europa. Extendido por un territorio enorme y de difícil adaptación, el Imperio carecía de la tecnología que parecería mínimamente necesaria para explicar esa cifra de población, considerable si se la compara con la de periodos posteriores, incluso el actual; una tecnología que incluyera al menos el uso de herramientas de hierro, vehículos de tracción y animales de tiro.

$\mathrm{Su}$ organización, por otro lado, es cierto que seguía muchos principios de carácter tribal, acordes, en buena lógica evolucionista, con otros datos de su estructura socioeconómica: una producción no mercantil y la inexistencia de la propiedad privada de la tierra y otros recursos, al menos con las implicaciones del sentido contemporáneo del concepto de propiedad. Pero en su territorio había ciudades, como Cuzco, y no hay duda de que existía también un Estado (había al menos un sistema de cargos públicos y un ejército), y la población estaba dividida en grupos sociales de distinto tipo (étnico-lingüísticos, profesionales, estamentales) con acceso desigual a la riqueza y al poder político. Diferente por ello de la formación tribal arquetípica, como eran muchas de las sociedades vecinas, sin embargo las formas de trabajo y dependencia en él no parece que fueran tampoco las relacionadas con la esclavitud en la Antigüedad clásica ni con las de la servidumbre de la gleba en la Edad Media europea; al menos no mayoritariamente. La subordinación y la dependencia no tenían en general formas individualizadas, sino que ponían en relación a personas por medio de las colectividades a las que pertenecieran o en las que estuvieran encuadradas (naciones, comunidades de aldea, grupos de artesanos, la élite imperial y sus linajes), aunque destacando sobre todas ellas la figura del emperador, "el Inca», dotada, desde luego, de un fuerte carácter religioso.

Obsérvese que en esta caracterización, la expresión «sistema económico" tiene un sentido más amplio que el que suele darle la ciencia económica de hoy en el análisis de las economías industriales o posindustriales contemporáneas, especialmente la ciencia de los economistas liberales o neoliberales, hoy tan influyente. Por "sistema económico" entendemos el conjunto de los factores y relaciones entre factores que hacen posible la reproducción de una sociedad (su población, sus relaciones sociales y sus instituciones) en las circunstancias de su tiempo histórico, tanto ecológicas y tecnológicas como de relación con las socieda- 
des vecinas. Desde la perspectiva de la ciencia económica liberal, el concepto hace referencia a factores que son propios de su objeto de estudio, pero también a otros que pueden considerarse ajenos a lo que es estrictamente la producción, distribución y consumo de bienes, y la prestación y obtención de servicios: como los factores derivados de la política, la religión y las diferencias sociales.

En los últimos veinte años, aproximadamente, la controversia sobre el sistema económico incaico apenas ha aparecido mencionada en la bibliografía. La mención a ella por Murra en su prólogo de 1977 a la publicación de su tesis doctoral, La organización económica del Estado inca (73), debió ser una de las últimas alusiones. En la historia de las investigaciones del imperio inca, estos veinte años constituyen un período que ofrece como novedad, precisamente, el estudio intensivo de aquellos aspectos de este imperio que son "no económicos" para el pensamiento economista más ortodoxo de hoy, como la cosmología, la mitología, los ritos religiosos, y la organización social y de las relaciones de parentesco; temas para los que cabe destacar los trabajos de R. T. Zuidema (74), P. Duviols (75) y G. Urton (76), entre otros investigadores.

Dado el concepto de sistema económico que hemos apuntado, estos trabajos no impiden teóricamente un acercamiento nuevo a la cuestión planteada en la polémica; antes al contrario. Pero el cambio de orientación que representan en las investigaciones ha podido favorecer la pérdida de interés en ella en la medida en que con estos trabajos no se ha contestado explícitamente a esa cuestión. Este ha podido ser especialmente el efecto en lectores que han seguido de cerca la publicación de estos estudios pero que están poco familiarizados con la bibliografía anterior a, digamos, 1973.

Hay una segunda razón, de más peso, que explica esa pérdida

(73) Murra, [58], 1978 [1955*], págs. 11-16.

(74) Ver por ejemplo The Ceque System of Cuzco, traducción de Eva M. Hooykas; Leyden, Países Bajos, E. J. Brill, International Archives of Ethnography, Supplement to Vol. 50, 1964. "Lieux sacrés et irrigation: tradition historique, mythes et rituels au Cuzco"; en Annales, $E$. $S$. C., vol. 33, número special: Anthropologie historique des sociétés andines, 1978, págs. 1.037-1.056.

(75) Ver por ejemplo "Algunas reflexiones acerca de las tesis de la estructura dual del poder incaico", en Revista Histórica de la Pontificia Universidad Católica del Perú, vol. 4, 1980, nó 2, págs. 183-96.

(76) Ver por ejemplo The History of a Myth: Pacariqtambo and the Origin of the Inkas. Austin, University of Texas Press, 1990 
de interés, y es que los estudios de los últimos veinte años que sí responden a esa cuestión no aluden apenas a la controversia, es decir, a la existencia (o posibilidad) de respuestas a ella discrepantes, seguramente por considerar que la polémica está ya superada; esto es, por considerar que hay ya por lo menos unas ideas básicas sobre el imperio inca y su sistema económico, así como sobre la metodología más adecuada para seguir avanzando en su conocimiento, que están fuera de discusión. La mayoría de estos estudios están basados en documentación de archivo dejada por la administración colonial española y son producto del creciente interés en este tipo de fuentes desde los años cincuenta, alimentado en primer lugar por M. Helmer, M. Rostworowski y W. Espinoza Soriano, además del citado J. Murra. Naturalmente, los mismos estudios han hecho crecer este interés, y como consecuencia de él, hoy se conoce ya un número relativamente considerable de estos documentos, que aparecen citados en la bibliografía de las últimas décadas si es que su publicación no forma ya parte de ella.

Las nuevas fuentes ofrecen información detallada sobre muchos territorios del imperio inca que están alejados de lo que fue su zona nuclear: los valles y sierras de lo que hoy es el centro y sur de Perú. Contrasta esto con la mayor parte de la información disponible hasta los años 70 , procedente sobre todo de lo que podemos llamar genéricamente "crónicas" (textos narrativos con información de carácter histórico en el sentido convencional de la expresión) y referida a dicha zona nuclear o al imperio inca tomado como un todo.

Ordenados de norte a sur, los territorios examinados a la luz de esta documentación de archivo son, entre otros, los valles centrales de la sierra ecuatoriana (77); la cuenca de Huánuco, en la sierra central de Perú (78); el valle del alto Mantaro, también

(77) Frank Salomon, "Vertical Politics on the Inka Frontier", en J. V. Murra, N. Wachtel y J. Revel, eds., Anthropological History of Andean Polities; Cambridge, Cambridge University, Press, 1986 [1978], págs. 89-117, Native Lords of Quito in the Age of the Incas: The Political Economy of North Andean Chiefdoms: Cambridge, Cambridge University Press, 1986.

(78) Craig MoRRIS, "Storage, Supply, and Redistribution in the Economy of the Inka State", en J. V. Murra, N. Wachtel y J. Revel, eds., Anthropological History of Andean Polities, Cambridge, Cambridge University Press, 1986 [1980*], págs. 59-68. Craig MORRIS y Donald E. ThOMPSON, "Huánuco Viejo: an Inca Redistributive Center, en American Antiquity, vol. 35, 1970, n² 3, págs. 344-62. 
en la sierra central peruana (79); los valles costeros del norte de Perú (80); el valle de Abancay, en la sierra meridional de Perú (81); las regiones de Carabaya y Chuquiabo, al nordeste y sudoeste, respectivamente, del lago Titicaca (82); y el valle de Cochabamba, en los límites orientales del altiplano boliviano (83).

En lo que sólo en apariencia es un efecto de la propia metodología utilizada en estos estudios regionales, predomina en ellos la idea de que el sistema ecónomico del imperio incaico consistía en la suma de todos los órdenes económicos de las unidades sociopolíticas que este imperio comprendía (el principal objeto de estos trabajos), más la economía política que sobre todos estos órdenes establecieron los incas y sus aliados como élite del poder imperial supremo. Tras su incorporación al Imperio, esas unidades pasaron a ser los kelementos constituyentes subimperiales" del mismo, en palabras de G. A. Collier (84); pero sus respectivas economías políticas continuaron asegurando su reproducción, a pesar del cambio en su status político como consecuencia de esa incorporación, y a pesar también, paradójicamente, de la reconocida interferencia de la economía estatal inca en ellos, considerada negativa para los «elementos subimperiales» por servir exclusivamente a los intereses de la clase gobernante. No obstante todo ello, se lee con frecuencia en esta bibliografía el argumento de que estos «elementos subimperiales» lograron sobrevivir la experiencia de la dominación incaica, como muchos soportarían después también la conquista española y hasta el

(79) Terence D'Altroy y Christine A. HASTORF, "The Distribution and Contents of Inca State Storehouses in the Xauxa Region of Peru", en American Antiquity, vol. 49, 1984, $\mathrm{n}^{\mathbf{2}} 2$, págs. 334-49. Terence D'AlTROY y Timothy EARLE, "Staple Finance, Wealth Finance, and Storage in the Inka Political Economy", en Current Anthropology, vol. 26, 1985, n² 2, págs. 187-206.

(80) Patricia NeTHERly, "The Management of Late Andean Irrigation Systems on the North Coast of Peru", en American Antiquity, vol. 49, 1984, n² 2, págs. 227 254.

(81) Waldemar EsPinOza Soriano, "El trabajo de los yanayacos en las tierras del Inca", en W. Espinoza Soriano, ed., Los modos de producción en el imperio de los incas, Lima, Amaru, 1981, [1973] págs. 299-328.

(82) Jean BERTHELOT, "L'exploitation des métaux précieux au temps des Incas", en Annales, E. S. C., vol. 33, 1978, numéro special: Anthropologie historique des sociétés andines, págs. 948-966.

(83) Nathan WACHTEL, "The Mitimas of the Cochabamba Valley", en G. A. Collier, R. I. Rosaldo y J. D. Wirth, eds., The Inca and Aztec States, 1400-1800: Anthropology and History, Nueva York, Academic Press, 1982, págs. 199-235.

(84) George A. Collier, "Introduction: In the Shadow of Empire; New Directions in Mesoamerican and Andean Ethnohistory", en G. A. Collier, R. I. Rosaldo y J. D. Wirth, eds., The Inca and Aztec States, 1400-1800: Anthropology and History, Nueva York, Academic Press, 1982, págs. 1-20; pág. 3. 
régimen colonial (85). Es lo que nosotros llamamos «la tesis de la continuidad de la cultura andina».

Sin embargo, lejos de poder entenderse como una tesis fundamental sobre la naturaleza del sistema económico que está fuera de toda discusión, es ésta una interpretación que puede ser entendida sin dificultades como una forma muy reciente del modelo de Smith/Cunow. Obsérvese que contrasta radicalmente con la opinión expresada por Vargas Llosa en el artículo citado al principio, que hemos elegido precisamente por tratarse de una reivindicación, también muy reciente, de la posición de Prescott: una reivindicación hecha por alguien que, sin ser un especialista en la materia, tiene sin embargo la suficiente talla intelectual (y el suficiente conocimiento de la historia de su país) como para que sus palabras merezcan ser tomadas en consideración. Es posible que la opinión del célebre escritor peruano no la comparta la gran mayoría de los investigadores actuales, especialmente fuera de los países andinos, pero la discrepancia que representa con respecto al modelo asumido mayoritariamente en los estudios regionales citados sugiere al menos que, contrariamente a lo que da a entender la bibliografía de los últimos años, las dos posiciones fundamentales que definen la controversia, si no su tono o ambiente, siguen vigentes.

No obstante, la creencia de que la controversia está ya superada es interesante como problema analítico, pues está en relación con la manera como se concibe la polémica entre los investigadores y, más allá, con la manera como se concibe entre ellos el progreso en los estudios del imperio incaico. Entender adecuadamente ambas cosas es naturalmente una condición indispensable para asegurar de verdad ese progreso, del que depende a su vez, entendemos nosotros, el potencial ilustrativo del imperio inca para el estudio de casos históricos comparables de los que se tiene menos información. La creencia es importante por ello como problema dentro de la problemática general de la controversia y es desde este punto de vista desde el que la tratamos nosotros aquí.

De hecho, la creencia es antigua y se ha expresado siempre en el marco de formas distintas de entender la polémica. No vamos a tratar aquí de esas formas (86), sino tan sólo de una premisa de la que parecen partir todas o la mayoría de ellas: la

(85) Véase, por ejemplo, ColliER [83], págs. 8-11.

(86) De nuevo remitimos al lector interesado a nuestro trabajo El problema de la comprensión..., [15]. 
de que la controversia es fundamentalmente el producto de la lectura de fuentes poco dignas de crédito, y que rehuyendo éstas y tomando en consideración sólo las más fiables o las únicas fiables, es como hay que llegar a la descripción correcta del imperio inca y con ello proponer el único modelo válido de su sistema económico.

Esta premisa aparece por primera vez en el trabajo citado de Marcos Jiménez de la Espada, y después en la obra de Cunow (87), Markham (88), Ph. A. Means (89), R. Levillier (90), $\AA$. Wedin (91) y, no hace mucho tiempo, F. Salomon (92).

Nosotros deseamos defender aquí una idea diferente: la de que si bien el estudio del imperio inca requiere naturalmente el análisis de sus fuentes, la controversia se ha manifestado a lo largo de la historia de la investigación con independencia de la consulta de fuentes específicas; esto es, que ni el manejo de estas fuentes ha conducido por sí solo a la superación de la polémica, ni la adopción de uno u otro de los dos modelos de interpretación que la dominan ha sido el resultado de seguir preferentemente una fuente en especial o una selección dada de fuentes. Lo que ha ocurrido es el fenómeno metodológico inverso: que el estudio de este imperio ha tenido siempre como referencia el tratamiento de problemas antropológicos e históricos que trascienden el caso, se haya reconocido esto o no, y que para sustentar sus posiciones con respecto a estos problemas, los investigadores han recurrido a aquellas fuentes que cada uno ha considerado más significativas, que pueden coincidir o variar con las manejadas por otro. Entre estos problemas generales está el del origen y razón del Estado, el de la importancia del cambio tecnológico en la explicación del cambio cultural, el de las razones de la desigualdad en sociedades que desconocen la propiedad privada (y a la inversa, el de los fundamentos de la sociedad justa e igualitaria que es a la vez próspera y compleja) y el de las relaciones de producción

(87) CunOW, [50], 1933 [1896].

(88) MARKHAM, [34].

(89) Philip Ainsworth MEans, "Biblioteca Andina, Part One, the Chroniclers, or, the Writers of the Sixteenth and Seven-teenth Centuries Who Treated of the Pre-Hispanic History and Culture of the Andean Countries"; en Connecticut Academv of Arts and Sciences Transactions, vol. 29, 1928, págs. 271-525. Ancient Civilizations of the Andes; Nueva York, Gordian Press, 1931.

(90) LEVILLIER, [59]

(91) Ake Wedin, El Concepto de lo incaico y las fuentes; Upsala, Suecia, Studia Historica Gothorburgensia, 1966.

(92) Salomon, [77], Native Lords of Quito. 
en sociedades estatales preindustriales para las que es difícil aplicar los modelos clásicos de esclavitud y servidumbre.

Sin agotar su contrastación con lo que ha sido la historia de los estudios del imperio inca, nuestra apreciación está basada en tres series de datos que ya nos parecen decisivos en primer lugar, la dependencia del tiempo de la disponibilidad de las fuentes, fenómeno que contrasta con la persistencia de la controversia; en segundo lugar, las notables diferencias entre los investigadores citados sobre la fiabilidad de las fuentes y por tanto sobre cuáles hay que seguir y cuáles no para tener una idea correcta del imperio incaico y su sistema económico; y en tercer lugar, la falta de correspondencia entre el uso de las fuentes y la alternativa fundamental de los dos modelos en la polémica.

(Continuará) 